\title{
An Automated Home-Cage System to Assess Learning and Performance of a Skilled Motor Task in a Mouse Model of Huntington's Disease
}

\author{
Cameron L. Woodard, ${ }^{1,2,3}$ Federico Bolaños, ${ }^{1,2,3}$ James D. Boyd, ${ }^{1,2}$ Gergely Silasi, ${ }^{4}$ Timothy H. \\ Murphy, ${ }^{1,2}$ and ${ }^{-}$Lynn A. Raymond ${ }^{1,2}$
}

DOI:http://dx.doi.org/10.1523/ENEURO.0141-17.2017

${ }^{1}$ Department of Psychiatry, Kinsmen Laboratory of Neurological Research, University of British Columbia, Vancouver, British Columbia V6T 1Z3, Canada, '2Djavad Mowafaghian Centre for Brain Health, University of British Columbia, Vancouver, British Columbia V6T 1Z3, Canada, ${ }^{3}$ Graduate Program in Neuroscience, University of British Columbia, Vancouver, British Columbia V6T 1Z3, Canada, and ${ }^{4}$ Department of Cellular and Molecular Medicine, Faculty of Medicine, University of Ottawa, Ottawa, Ontario K1H 8M5, Canada

\section{Visual Abstract}
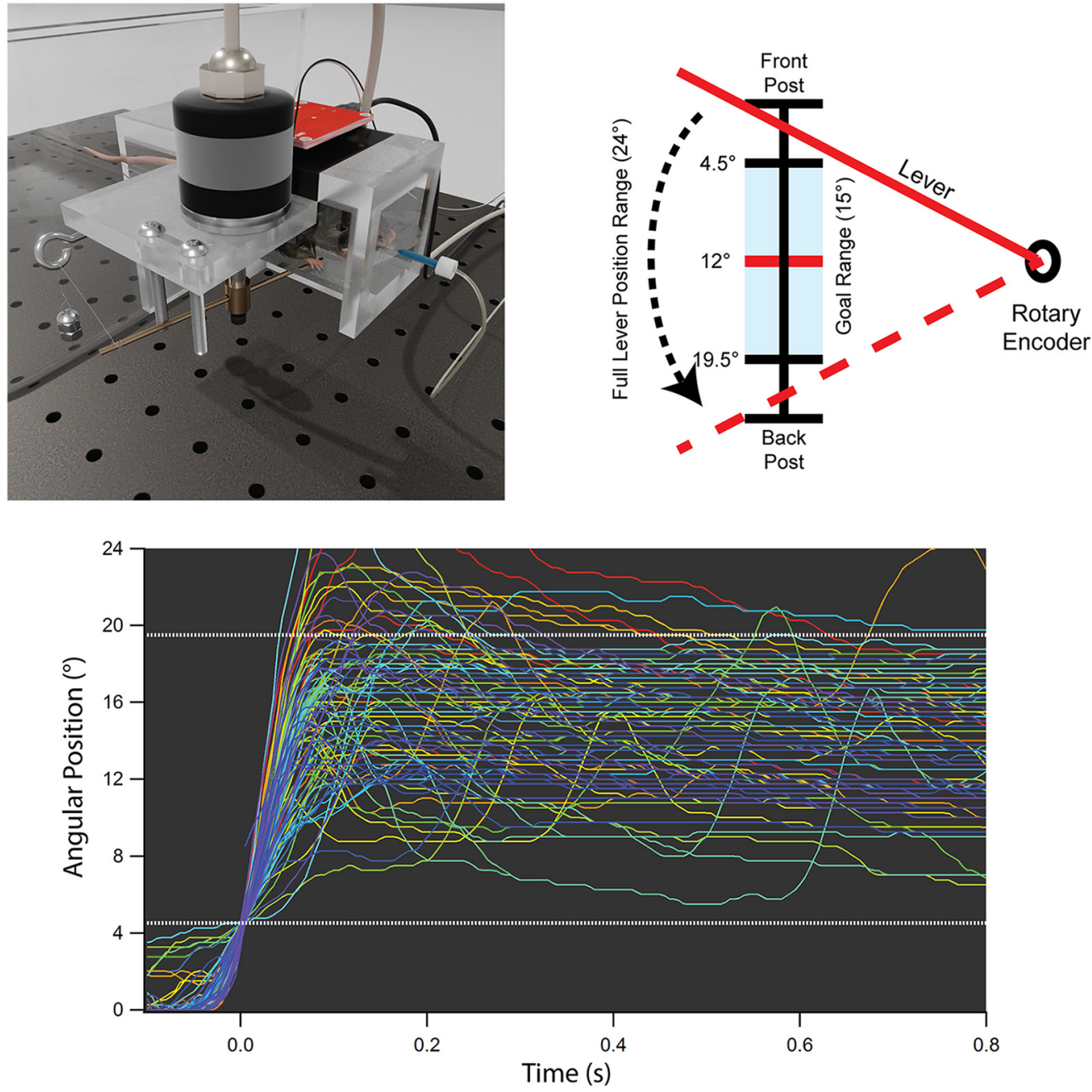


\section{Significance Statement}

Difficulty with the learning and performance of skilled motor tasks is a common feature observed in many movement disorders, including Huntington's disease (HD) and Parkinson's disease. Modeling these characteristics is an important goal in our ongoing effort to understand the mechanisms by which these diseases progress, as well as in the search for prospective therapies. In this article, we use an automated behavioral testing system to assess learning and performance of a lever positioning task in a mouse model of HD, revealing several parallels with the human disease. We hope that this methodology will provide a more high-throughput platform for the behavioral screening of drugs that may help in the treatment of $\mathrm{HD}$ and similar diseases.

Behavioral testing is a critical step in assessing the validity of rodent models of neurodegenerative disease, as well as evaluating the efficacy of pharmacological interventions. In models of Huntington's disease (HD), a gradual progression of impairments is observed across ages, increasing the need for sensitive, high-throughput and longitudinal assessments. Recently, a number of automated systems have been developed to perform behavioral profiling of animals within their own home-cage, allowing for 24-h monitoring and minimizing experimenter interaction. However, as of yet, few of these have had functionality for the assessment of skilled motor learning, a relevant behavior for movement disorders such as HD. To address this, we assess a lever positioning task within the mouse home-cage. Animals first acquire a simple operant response, before moving to a second phase where they must learn to hold the lever for progressively longer in a rewarded position range. Testing with this paradigm has revealed the presence of distinct phenotypes in the YAC128 mouse model of HD at three early symptomatic time points. YAC128 mice at two months old, but not older, had a motor learning deficit when required to adapt their response to changes in task requirements. In contrast, six-month-old YAC128 mice had disruptions of normal circadian activity and displayed kinematic abnormalities during performance of the task, suggesting an impairment in motor control. This system holds promise for facilitating high throughput behavioral assessment of HD mouse models for preclinical therapeutic screening.

Key words: home-cage; Huntington's disease; kinematic analysis; motor learning; novel methods

\section{Introduction}

The past several decades have seen the widespread development and application of transgenic mouse models for the study of brain disorders. These animal models serve both to elucidate the underlying mechanisms of genetic disorders, as well as provide a platform for the pre-clinical screening of potential therapeutic interventions. Huntington's disease (HD), an autosomal dominant genetic disorder, is one such disease that has benefited from genetic modeling in mice. HD is caused by a trinu-

Received April 21, 2017; accepted August 30, 2017; First published September 07, 2017.

The authors declare no competing financial interests.

Author contributions: C.L.W., F.B., G.S., L.A.R., and T.H.M. designed research; C.L.W. performed research; J.D.B. and F.B. contributed unpublished reagents/analytic tools; C.L.W., J.D.B., and F.B. analyzed data; C.L.W. and L.A.R. wrote the paper.

This work was supported by Canadian Institutes of Health Research (CIHR) Grants FDN-143-210 (to L.A.R.) and FDN-143209 (to T.H.M.). T.H.M. was supported by Brain Canada and the Canadian Neurophotonics Platform.

Acknowledgments: We thank Luis Bolaños for his assistance with figures.

Correspondence should be addressed to either of the following: Lynn A. Raymond, 2255 Wesbrook Mall, Detwiller Pavilion Room 4834, University of British Columbia, Vancouver BC V6T 1Z3, Canada, E-mail: lynn.raymond@ubc.ca; or Timothy H. Murphy, 2255 Wesbrook Mall, Detwiller Pavilion Room 4842, University of British Columbia, Vancouver BC V6T 1Z3, Canada, E-mail: thmurphy@mail.ubc.ca.

DOI:http://dx.doi.org/10.1523/ENEURO.0141-17.2017

Copyright (C) 2017 Woodard et al.

This is an open-access article distributed under the terms of the Creative Commons Attribution 4.0 International license, which permits unrestricted use, distribution and reproduction in any medium provided that the original work is properly attributed. cleotide repeat expansion on the gene huntingtin (HTT; Huntington's Disease Collaborative Research Group, 1993), and mutation carriers most often show a progressive deterioration in motor function starting in middle-age (Kirkwood et al., 2001). However, HD is not solely a movement disorder; cognitive decline is eventually observed in all patients, and deficits on certain cognitive and motor tasks can precede the onset of disease diagnosis by 10-15 years (Paulsen et al., 2008). In addition, psychiatric illness, primarily depression, is highly comorbid with both pre-symptomatic and clinical HD (Kirkwood et al., 2001; Julien et al., 2007).

To date, over 50 distinct mouse and rat models of HD have been developed (Pouladi et al., 2013; Menalled et al., 2014), and behavioral testing is a critical step in determining how closely aligned the animal's phenotype is with human symptomatology (often referred to as the "face validity" of the model). The YAC128 mouse model expresses the human full-length $H T T$ gene with $128 \mathrm{CAG}$ repeats on a yeast artificial chromosome construct, and has been well established to show many of the behavioral and pathophysiological features of the human disease (Slow et al., 2003). These animals display motor and balance deficits, as well as cognitive impairments in learning, memory and strategy shifting starting as early as two months old (for review, see Abada and Ellenbroek, 2016). However, conflicting results have been reported concerning the time frame, severity and progression of some behavioral phenotypes, including motor learning (Van Raamsdonk et al., 2005; Menalled et al., 2009; Brooks 
et al., 2012a). Although differences in methodology and apparatus may be contributing to this variability in behavioral outcome measures (Mandillo et al., 2008), other factors likely include the variable expressivity of behavioral phenotypes between animals, and the testing of insufficiently large experimental groups.

To address these issues, importance must be placed on finding novel ways to assess behavior that reduce confounding factors and increase throughput. In recent years, several systems have become commercially available which increase the automation of behavioral testing and analysis by assessing animals within their home-cage (e.g., Intellicage; NewBehavior AG). These systems have the combined benefits of increasing the throughput of behavioral phenotyping, eliminating the subjectivity associated with manual scoring, increasing the length of the testing period and reducing the amount of animal-experimenter interaction (Hånell and Marklund, 2014). Two recent papers have applied these paradigms to great success in HD models, using computer vision techniques in combination with machine learning to develop a comprehensive behavioral profile for a set of HD animal models (Balci et al., 2013; Alexandrov et al., 2016).

Recently, interest has been growing in the development of automated systems for the assessment of skilled motor tasks (Fenrich et al., 2015; Sindhurakar et al., 2017). Although rotarod and other full body coordination tasks are sensitive in capturing one aspect of motor function and balance, they may not detect more subtle motor learning and movement kinematic phenotypes relevant to HD. To address this, we have employed a lever-positioning task that integrates into the animal's home cage, and is accessible by group-housed mice full-time over several weeks of testing. This task is learned in a selfdirected manner, and following initial acquisition of a simple operant response, task demands change dynamically to probe motor learning and behavioral flexibility. Additionally, this system collects kinematic measures of task performance, allowing for the measurement and detection of motor abnormalities. In the present article, we report our results from using this system for the assessment of several motor, circadian and cognitive phenotypes in the YAC128 model at two, four, and six months of age. We found that while two-month-old YAC128 mice had difficulties with adapting their motor behavior in response to changes in task demands, older mice did not show this problem. Conversely, alterations in the kinematics of task performance were evident in six-month-old mice, but not seen in the younger animals. Additionally, YAC128 mice across ages had circadian abnormalities in the distribution of their trials, and a greater number failed to acquire the task as compared to WT.

\section{Materials and Methods}

\section{Animal housing, husbandry, and genotyping}

A colony of heterozygous YAC128 mice on the FVB/N background (YAC128 line 53, RRID:MGI:3613525; Slow et al., 2003) was maintained by breeding with wildtype FVB/N animals. Animals were housed in cages of two to five male littermates on a 12/12 h light/dark cycle in a temperature- and humidity-controlled room. A total of 123 male WT and YAC128 animals were used for experiments, and all procedures were conducted in accordance with the Canadian Council on Animal Care and approved by the University of British Columbia Committee on Animal Care. Until the start of testing, animals were allowed ad libitum access to standard lab chow and water. Animal tissue was collected via ear clipping at weaning, and DNA extraction and PCR analysis were subsequently used to determine genotype, as previously described (Slow et al., 2003). As the experiments involved minimal experimenter interaction or handling of the mice, and no subjective analysis was performed, the experimenter was not blinded to genotype.

\section{RFID microchip implantation}

Glass RFID capsules (Sparkfun, SEN-09416) were implanted into all animals before behavioral testing as described in Bolaños et al. (2017). Briefly, surgical plane was induced with $4 \%$ isofluorane in an induction chamber, followed by a switch to $1.5 \%$ isofluorane for maintenance. The thoracic torso was disinfected with betadine and a sterile injector (Fofia, ZS006) was used to penetrate the dermal layer and insert the RFID capsule below the nape of the neck. Buprenorphine was administered via subcutaneous injection $(0.05 \mathrm{mg} / \mathrm{kg})$ and animals were allowed to recover from anesthesia while being monitored for signs of pain. Animals were moved back to their homecage and checked again $24 \mathrm{~h}$ later to ensure normal behavior and proper placement of microchips.

\section{Description of apparatus}

All experiments were performed in a modified mouse home-cage (referred to herein as the "lever-cage"), with a custom designed Plexiglas rectangular prism chamber $(2.5 \times 2.5 \times 9.5 \mathrm{~cm})$ attached to one side, $6 \mathrm{~cm}$ from the floor of the cage (Fig. 1A,B). This chamber is closed on all sides except for an opening leading into the cage, and a second narrow opening of $3 \mathrm{~cm}$ along the bottom of the right wall at the end opposite the cage entrance. A cylindrical steel rod ( $2 \mathrm{~mm}$ thick) extends through this opening $\sim 1 \mathrm{~cm}$ into the chamber. This rod is movable on a horizontal axis, restricted to a range of $24^{\circ}$ by two metal posts, and held in its "starting" position by a 1.5-g counterweight (Fig. 1C). The lever is also attached to a rotary encoder (Phidgets, ISC3004) to measure and record all movements. On the far wall of the chamber adjacent to the lever, a spout (blunted 21-G needle) dispenses water drops, and is attached to a computer-controlled valve and water supply (Murphy et al., 2016). An RFID antenna and reader (Sparkfun) is inset into the ceiling of the chamber to individually identify microchipped animals. A description of the water delivery system and RFID tag electronics and software can be found in Murphy et al. (2016) and Bolaños et al. (2017). All components are controlled by customized software running on a Raspberry Pi single-board computer. Mice are provided with free access to chow and have standard environmental enrichment within the cage (bedding, hut, PVC tube). 


\section{A}

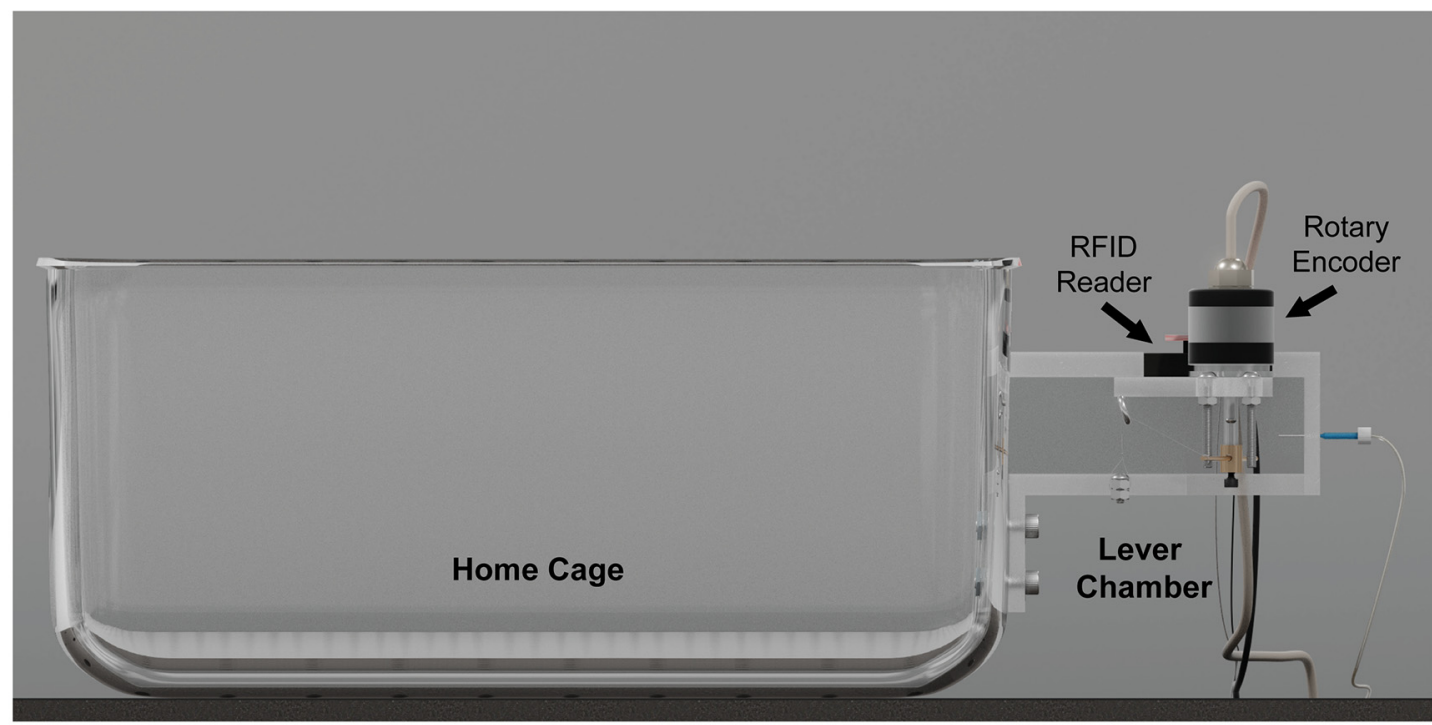

B

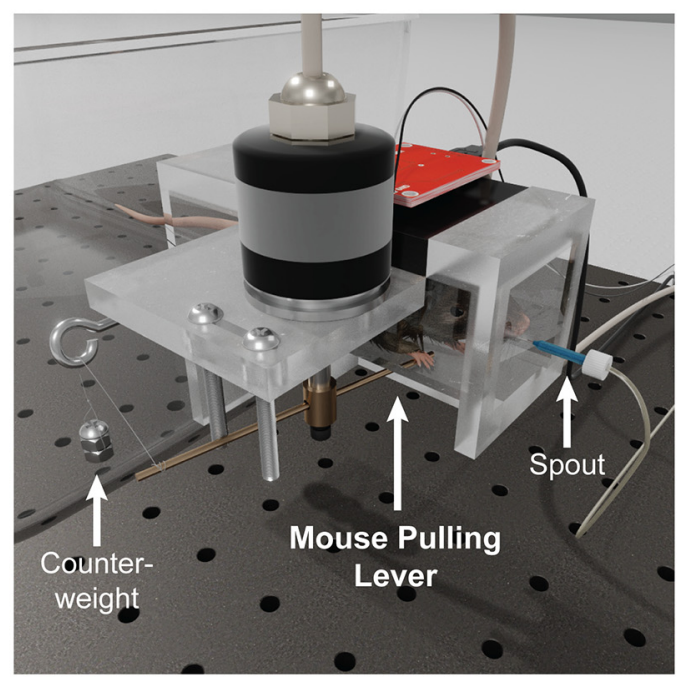

C

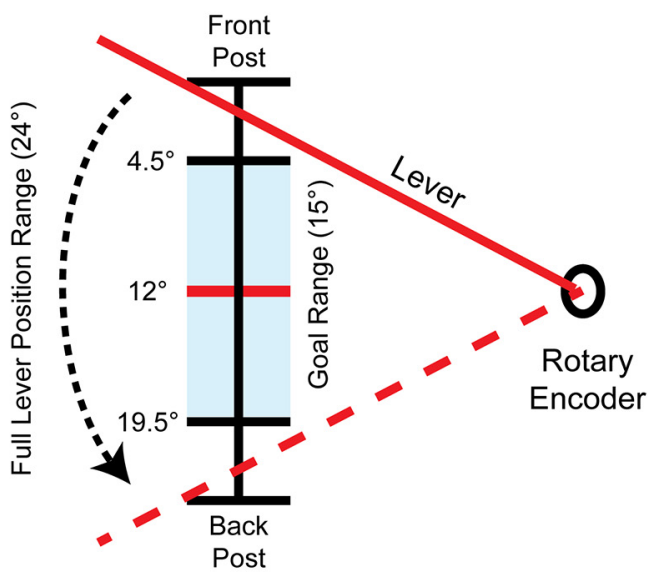

Figure 1. Apparatus for home-cage assessment of skilled motor learning. A, A small opening on one side of the home-cage allows $24-\mathrm{h}$ access to a chamber containing a metal lever and water spout. Microchipped animals are identified by an RFID reader on entrance into the chamber, allowing for individual tracking and assessment of group-housed animals. $\boldsymbol{B}$, The lever is restricted in its horizontal movement by two metal posts, and held in starting position by a small counterweight. In the first phase of testing, the mouse must pull the lever backwards $12^{\circ}$ from its starting position to receive a water drop. $\mathbf{C}$, A top-down view of the lever position range. In the second phase of testing, the mouse must first pull the lever back to the center (red line), and then hold it within a central goal position range (shaded area) to receive a water drop. The length of time the lever must be held for changes dynamically based on the individual animal's success rate.

\section{Behavioral testing}

Animals were transferred to an animal facility following RFID microchipping and allowed to recover and habituate for a minimum of $5 \mathrm{~d}$ before the start of testing. Naïve animals began the testing protocol at 60,120 , or $180 \mathrm{~d}$ old $( \pm 5 \mathrm{~d})$. Animals were tested alongside their littermates in mixed genotype groups of two to five animals per cage.

In the initial phase of testing (phase 1), naïve animals were introduced to the lever-cage and allowed to explore and discover the chamber. Entrance into the chamber by an animal triggered the RFID reader, resulting in the de- livery of a single water drop $(5 \mu l)$ from the reward spout, up to a maximum of 200 drops per day. Additional water drops $(10 \mu l)$ could be obtained on a continuous reinforcement schedule by pulling the lever backwards past the center of its movable range ( $12^{\circ}$ from starting position). The chamber was accessible to animals $24 \mathrm{~h} / \mathrm{d}$, and the timing of each entrance, exit, and trial was automatically collected and saved. Additionally, the position trace of the lever during each trial was recorded for kinematic analysis. This initial testing period lasted from 3-8 d, and animals were not disturbed once introduced to the cage 
except for semi-weekly weighing and bedding changes. Animals that did not perform $>200$ trials during this initial acquisition period were removed from the cage and not used for further testing (Fig. 2A; Table 1). Additionally, one six-month-old YAC128 mouse lost $>15 \%$ body weight during this initial testing period and was removed from the cage and not used for analysis (Table 1).

Following acquisition of the basic lever-pull task, animals were moved to a second phase (phase 2) where the criteria to receive a water drop changed. As before, the animal was required to displace the lever to the center of its movable range. However instead of immediately receiving a drop, the lever then had to be held in a central "goal range" (between $4.5^{\circ}$ and $19.5^{\circ}$ from start position) for a prescribed length of time before a drop was dispensed (Fig. 1C). If the lever was not held in the range for the required duration, a failed trial was recorded and no water was dispensed. Initially, this hold duration was set to a minimum of $100 \mathrm{~ms}$ for all animals, but this could increase based on the animal's performance of the task. Every 25 trials, a ratio of successful to failed trials was calculated for that animal; if the animal had a $>75 \%$ success rate over this block, then the required hold duration increased by $100 \mathrm{~ms}$, to a maximum of $800 \mathrm{~ms}$ (an end goal that the large majority of animals were able to achieve in pilot experiments). If the animal was $<10 \%$ successful, the required hold duration decreased by 100 ms. Otherwise, the hold duration remained the same for the subsequent block of trials. After $7 \mathrm{~d}$ in phase 2, animals were removed from the lever-cage and returned to their regular home-cage. Only five animals did not reach the maximum hold duration within the $7 \mathrm{~d}$ (Table 1).

\section{Data analysis and statistics}

All task performance data were automatically recorded into text files by the lever-cage software and were subsequently extracted and analyzed by customized scripts using IGOR Pro (Wavemetrics, RRID:SCR_000325). For analysis of kinematic measures in phase 2, all successful trials at the maximum hold duration $(800 \mathrm{~ms})$ were averaged to determine mean maximum displacement, speed, and slope of trajectory for each animal. Only animals with a minimum of 200 eligible trials before the end of testing were used to obtain a representative average and reduce the effect of intertrial variability. During the course of testing, some animals were excluded from analysis at intermediary stages because of system crashes that resulted in interruption of task access, and several other animals were excluded because of faulty data collection or program errors that led to nonstandard task advancement. Numbers of animals used for each analysis are indicated in figure legends, and numbers of animals excluded, with reasons why, are summarized in Table 1.

All statistical analyses were performed using GraphPad Prism 6.01 (GraphPad Software, RRID:SCR_002798). For most datasets, regular or repeated measures two-way ANOVA (as appropriate) with Bonferroni post hoc tests was used for statistical analysis of main/interaction effects. For the analysis of trials performed per day, a log transformation was used to normalize the data to allow for the use of two-way ANOVA, as several of the groups had a strong right skew in their distribution. For the analysis of time spent in the lever chamber, a significantly nonGaussian distribution was seen in many of the groups, limiting the use of two-way ANOVA. Paired comparisons between genotypes at each age group using either Student's $t$ tests or Mann-Whitney tests was performed, in addition to Kruskal-Wallis tests with Dunn's post hoc tests to analyze age effects in each genotype group. Fisher's exact test was used to compare the proportion of animals that reached criteria in phase 1 and reached the maximum hold duration in phase 2. A full summary of statistical results can be found in Table 2 .

\section{Results}

\section{WT and YAC128 mice rapidly acquire the task}

The large majority of WT and YAC128 animals ( 90\%) tested in all age groups successfully acquired the basic lever pulling task, and reached the performance criteria of 200 trials in phase 1. There was no difference in the proportion of animals that acquired the task between age groups or between genotypes within each age group, but there was an overall greater proportion of YAC128 animals that failed to reach the performance criteria within phase 1 as compared to WT ( $p=0.0386$; Fig. $2 A$ ). During the first few days of testing, some animals (especially at six months old) dropped in weight in response to the removal of ad libitum water. However, all but one animal recovered to within $10 \%$ of baseline weight after one week, and two-month-old WT mice gained weight over this period $(p=0.0485)$. Two-month-old mice, as well as four-month-old YAC128 mice, gained weight overall by the end of testing (two-month WT: $p=0.0001$; two-month YAC128: $p=0.0004$; four-month YAC128: $p=0.0211$ ), whereas four-month-old WTs and six-month-old mice showed no change (Fig. 2B).

A substantial amount of interanimal variability was observed in the frequency of task performance among WT and YAC128 mice, with mice typically performing an average of $300-500$ trials per day (Fig. $2 C$ ). An overall age effect was seen on trial frequency $(p=0.0106)$, with younger mice tending to have more trials per day, but no genotype differences were observed. A significant age effect was also seen in the amount of time spent in the testing chamber per day for both WT $(p=0.0005)$ and YAC128 $(p=0.0012)$ mice, with two-month-old animals higher on this measure than older animals (Fig. 2D). While some mice developed a relatively consistent strategy by the fifth day of testing, others were more variable in their performance, although no consistent genotype differences were observed (Fig. 2E,F).

\section{YAC128 mice display circadian abnormalities}

Performance of the task was distributed throughout the day for individual animals, but an increase in activity was almost always observed during the first $6 \mathrm{~h}$ of the dark phase (Fig. $3 A$ ). Interestingly, when the overall proportion of light versus dark phase trials was analyzed, YAC128 mice were found to have significantly higher light phase activity than WT mice overall (genotype: $p=0.0317$; Fig. 
A

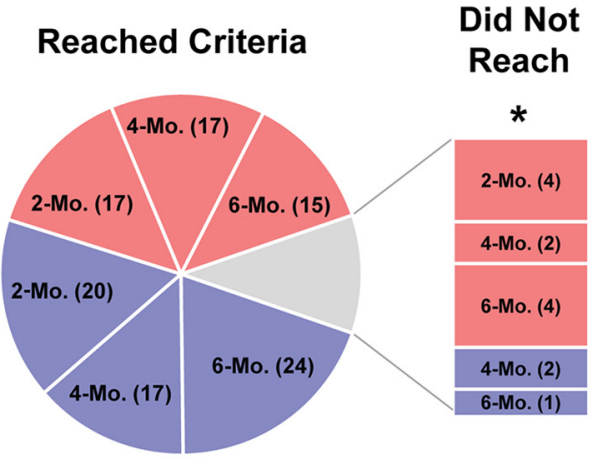

"WT $\because$ YAC128
B

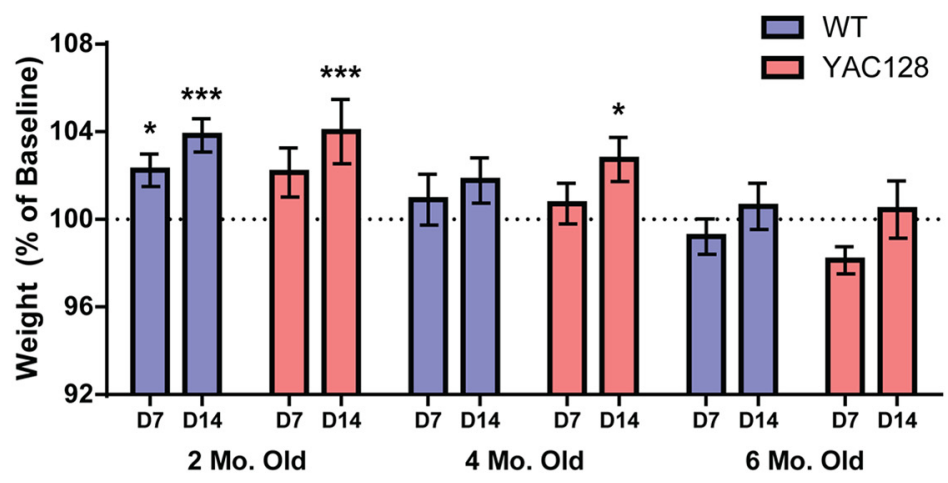

D
C

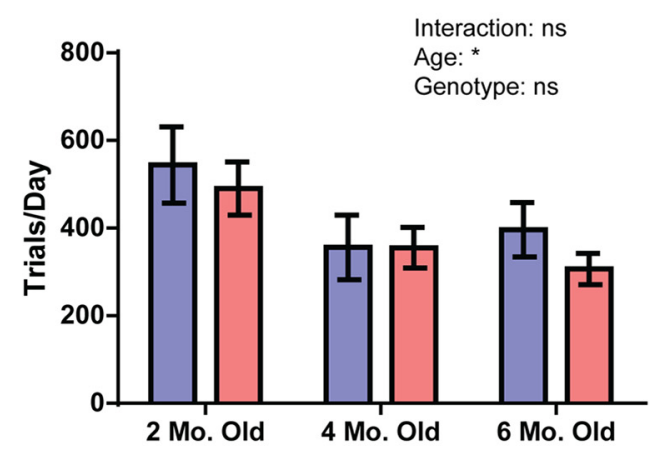

E

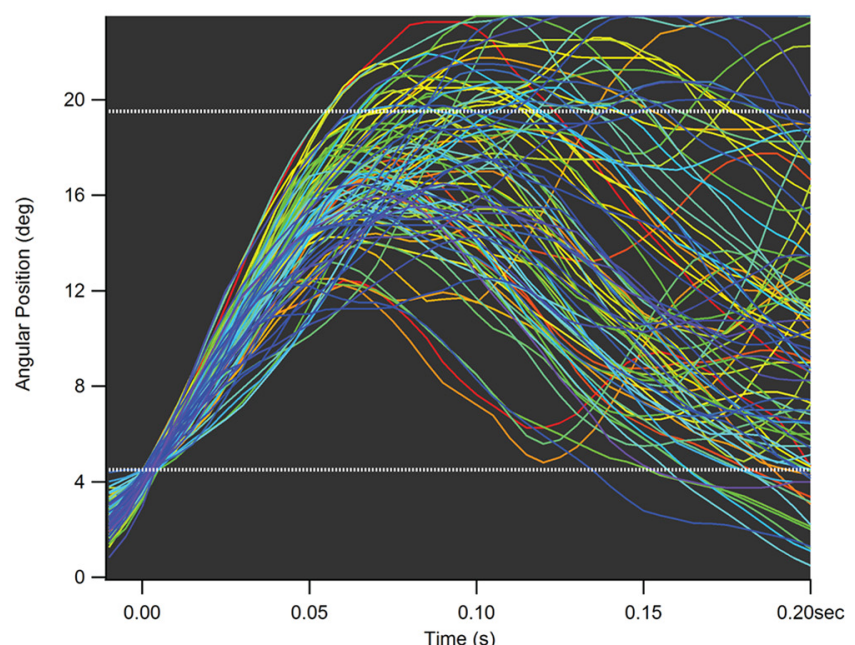

F

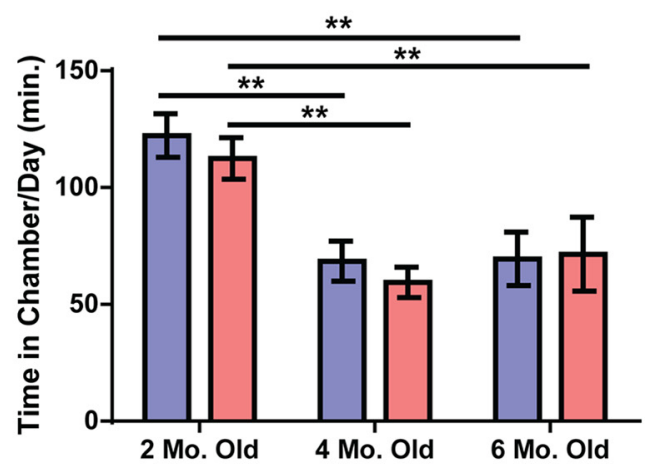

Figure 2. Acquisition and performance of lever-pull task in phase 1. $\boldsymbol{A}$, Number of animals to reach the performance criteria of 200 trials performed in phase 1. An overall lower proportion of YAC128 animals acquired the task as assessed by this cutoff. $\boldsymbol{B}$, Average weight over the course of testing as a percentage of baseline. Although six-month-old animals remained at their baseline weight, two-month-old WT and YAC128 animals and four-month-old YAC128 animals gained weight over $14 \mathrm{~d}$ in the lever-cage (asterisks indicate significant increase as compared to baseline weight). $\boldsymbol{C}$, No significant differences between WT and YAC128 were seen in the number of trials performed per day; however, animals in both genotypes performed less daily trials with increasing age. $\boldsymbol{D}$, Time spent in the chamber per day was also not significantly different between genotypes; however, both WT and YAC128 animals were much higher on this measure at two months old than at other ages. $\boldsymbol{E}, \boldsymbol{F}$, Sample lever traces from two four-month-old animals (WT and YAC128, respectively) in phase 1. Each line represents one trial. Numbers of animals (WT/YAC128) used for weight, trial frequency, and time in chamber analysis are $n=17 / 13$ at two months old, $n=14 / 16$ at four months old, and $n=18 / 12$ at six months old. All data are presented as mean \pm SEM. ns $=$ not significant; $* p<0.5 ; * * p<0.01 ; * * * p<0.001 ; * * * * p<0.0001$. 
Table 1. Animals excluded from analysis

\begin{tabular}{|c|c|c|c|c|c|}
\hline & $\begin{array}{l}\text { Animals initially } \\
\text { available for testing }\end{array}$ & $\begin{array}{l}\text { Did not reach } \\
\text { criteria in phase } 1\end{array}$ & $\begin{array}{l}\text { Did not reach } \\
\text { maximum hold duration }\end{array}$ & $\begin{array}{l}\text { Cage crash or } \\
\text { malfunction }\end{array}$ & $\begin{array}{l}\text { Excessive } \\
\text { weight loss }\end{array}$ \\
\hline Four months old & 19 WT/19 YAC128 & 2 WT/2 YAC128 & 2 WT/1 YAC128 & 5 WT/3 YAC128 & 0 WT/0 YAC128 \\
\hline
\end{tabular}

$3 B$ ). To more closely examine this, we binned each animal's trials by hour of day, and analyzed the average trial distribution for WT and YAC128 mice. While two-monthold YAC128 animals had no circadian abnormalities, there was a strong interaction between genotype and the timing of trials throughout the day in four-month-old $(p=0.0006)$ and six-month-old mice $(p=0.0066$; Fig. 3C-E). YAC128 mice at these ages tended to increase their trial performance in the last $3 \mathrm{~h}$ of the light phase, and then drop steeply $2 \mathrm{~h}$ after the start of the dark phase, whereas WT mice maintained a higher trial performance rate through the first $6 \mathrm{~h}$ of the dark phase.

\section{Two-month-old YAC128 mice are impaired at adapting} their motor response to changes in task demands

In phase 2, animals were required to hold the lever for progressively longer within a designated position range to receive water rewards. The way in which they progressed was based on their success rate at the current required hold duration, such that if over $75 \%$ of their trials in a 25-trial bin were held for the required length of time, the hold duration increased incrementally by $100 \mathrm{~ms}$. Animals that were more successful at adapting to these changing demands had a higher success rate and consequently a faster progression to the maximum hold duration (800

Table 2. Statistical table of all analyses

\begin{tabular}{|c|c|c|c|}
\hline & Data structure & Type of test & Test values and power \\
\hline Fig. $2 A$ & $\mathrm{~N} / \mathrm{A}$ & Fisher's exact test & $p=0.0386$ \\
\hline Fig. $2 B$, two months & $\begin{array}{l}\text { All but one group normally distributed } \\
\text { (D7 WT) }\end{array}$ & $\begin{array}{l}\text { Repeated measures two-way } \\
\text { ANOVA with Bonferroni } \\
\text { post hoc tests }\end{array}$ & $\begin{array}{l}\text { Days in cage: } F_{(2,56)}=20.11, p<0.0001 ; \text { genotype: } F_{(1,28)}=0.0007, p=0.9798 \\
\quad \text { interaction: } F_{(2,56)}=0.0260, p=0.9743\end{array}$ \\
\hline Fig. $2 B$, four months & All groups normally distributed & $\begin{array}{l}\text { Repeated measures two-way } \\
\text { ANOVA with Bonferroni } \\
\text { post hoc tests }\end{array}$ & $\begin{array}{l}\text { Days in cage: } F_{(2,56)}=6.050, p=0.0042 \text {; genotype: } F_{(1,28)}=0.08113, p= \\
\quad 0.7779 \text {; interaction: } F_{(2,56)}=0.4340, p=0.6501\end{array}$ \\
\hline Fig. $2 B$, six months & All groups normally distributed & $\begin{array}{l}\text { Repeated measures two-way } \\
\text { ANOVA with Bonferroni } \\
\text { post hoc tests }\end{array}$ & $\begin{array}{l}\text { Days in cage: } F_{(2,56)}=3.936, p=0.0252 ; \text { genotype: } F_{(1,28)}=0.2267, p=0.6376 \text {; } \\
\quad \text { interaction: } F_{(2,56)}=0.3738, p=0.6898\end{array}$ \\
\hline $\begin{array}{l}\text { Fig. } 2 C \text { (log } \\
\text { transform) }\end{array}$ & $\begin{array}{l}\text { All but one group (six-month YAC128) } \\
\text { normally distributed, equal } \\
\text { variances }\end{array}$ & Two-way ANOVA & $\begin{array}{l}\text { Age: } F_{(2,84)}=4.803, p=0.0106 ; \text { genotype: } F_{(1,84)}=0.1089, p=0.7422 \\
\quad \text { interaction: } F_{(2,84)}=0.5332, p=0.5887\end{array}$ \\
\hline Fig. $2 D$, two months & Normal distribution, equal variances & Student's $t$ test & $t_{(28)}=0.7433, p=0.4635$ \\
\hline Fig. $2 D$, four months & Non-normal distribution & Mann-Whitney test & $U=94, p=0.4659$ \\
\hline Fig. $2 D$, six months & Non-normal distribution & Mann-Whitney test & $U=107, p=0.9665$ \\
\hline Fig. $2 D$, WT & Non-normal distribution & $\begin{array}{l}\text { Kruskal-Wallis Test with } \\
\text { Dunn's post hoc tests }\end{array}$ & $H=15.22, p=0.0005$ \\
\hline Fig. $2 D$, YAC128 & Non-normal distribution & $\begin{array}{l}\text { Kruskal-Wallis Test with } \\
\text { Dunn's post hoc tests }\end{array}$ & $H=13.50, p=0.0012$ \\
\hline Fig. $3 B$ & $\begin{array}{l}\text { Groups normally distributed, equal } \\
\text { variances }\end{array}$ & Two-way ANOVA & $\begin{array}{l}\text { Age: } F_{(2,84)}=2.945, p=0.0580 ; \text { genotype: } F_{(1,84)}=4.772, p=0.0317 \\
\quad \text { interaction: } F_{(2,84)}=0.2492, p=0.7800\end{array}$ \\
\hline Fig. $3 C$ & Groups normally distributed & $\begin{array}{l}\text { Repeated measures two-way } \\
\text { ANOVA }\end{array}$ & $\begin{array}{l}\text { Hour of day: } F_{(23,644)}=86.51, p<0.0001 \text {; genotype: } F_{(1,28)}=-0.3218, p> \\
\quad 0.9999 ; \text { interaction: } F_{(23,644)}=0.7632, p=0.7788\end{array}$ \\
\hline Fig. $3 D$ & Groups normally distributed & $\begin{array}{l}\text { Repeated measures two-way } \\
\text { ANOVA with Bonferroni } \\
\text { post hoc tests }\end{array}$ & $\begin{array}{l}\text { Hour of day: } F_{(23,598)}=56.36, p<0.0001 ; \text { genotype: } F_{(1,26)}=0.0, p>0.9999 \\
\quad \text { interaction: }\end{array}$ \\
\hline Fig. $3 E$ & Groups normally distributed & $\begin{array}{l}\text { Repeated measures two-way } \\
\text { ANOVA with Bonferroni } \\
\text { post hoc tests }\end{array}$ & $\begin{array}{l}\text { Hour of day: } F_{(23,644)}=43.87, p<0.0001 ; \text { genotype: } F_{(1,28)}=0.8750, p= \\
\quad 0.3576 \text {; interaction: } F_{(23,644)}=1.911, p=0.0066\end{array}$ \\
\hline Fig. $4 A$ & Groups normally distributed & $\begin{array}{l}\text { Repeated measures two-way } \\
\text { ANOVA with Bonferroni } \\
\text { post hoc tests }\end{array}$ & $\begin{array}{l}\text { Trial number: } F_{(20,500)}=70.42, p<0.0001 \text {; genotype: } F_{(1,25)}=6.367, p= \\
\quad 0.0184 \text {; interaction: } F_{(20,500)}=5.321, p<0.0001\end{array}$ \\
\hline Fig. $4 B$ & Groups normally distributed & $\begin{array}{l}\text { Repeated measures two-way } \\
\text { ANOVA }\end{array}$ & $\begin{array}{l}\text { Trial number: } F_{(20,460)}=115.8, p<0.0001 \text {; genotype: } F_{(1,23)}=0.02924, p= \\
\quad 0.8657 \text {; interaction: } F_{(20,460)}=0.6740, p=0.8528\end{array}$ \\
\hline Fig. $4 C$ & Groups normally distributed & $\begin{array}{l}\text { Repeated measures two-way } \\
\text { ANOVA }\end{array}$ & $\begin{array}{l}\text { Trial number: } F_{(20,520)}=115.7, p<0.0001 \text {; genotype: } F_{(1,26)}=0.2737, p= \\
\quad 0.6053 \text {; interaction: } F_{(20,520)}=1.336, p=0.1497\end{array}$ \\
\hline Fig. $4 D$ & $\mathrm{~N} / \mathrm{A}$ & Fisher's exact test & $p=0.7292$ \\
\hline Fig. $4 E$ & $\begin{array}{l}\text { Groups normally distributed, equal } \\
\text { variances }\end{array}$ & Two-way ANOVA & $\begin{array}{l}\text { Age: } F_{(2,74)}=2.753, p=0.0703 ; \text { genotype: } F_{(1,74)}=2.002, p=0.1613 \\
\quad \text { interaction: } F_{(2,74)}=1.504, p=0.2290\end{array}$ \\
\hline Fig. $5 E$ & $\begin{array}{l}\text { Groups normally distributed, equal } \\
\text { variances }\end{array}$ & $\begin{array}{l}\text { Two-way ANOVA with } \\
\text { Bonferroni post hoc tests }\end{array}$ & $\begin{array}{l}\text { Age: } F_{(2,64)}=3.193, p=0.0477 ; \text { genotype: } F_{(1,64)}=2.798, p=0.0993 \\
\quad \text { interaction: } F_{(2,64)}=2.522, p=0.0883\end{array}$ \\
\hline Fig. $5 F$ & $\begin{array}{l}\text { All but one group (two-month } \\
\text { YAC128) normally distributed, } \\
\text { equal variances }\end{array}$ & $\begin{array}{l}\text { Two-way ANOVA with } \\
\text { Bonferroni post hoc tests }\end{array}$ & $\begin{array}{l}\text { Age: } F_{(2,64)}=0.8329, p=0.4395 ; \text { genotype: } F_{(1,64)}=3.837, p=0.0545 \\
\quad \text { interaction: } F_{(2,64)}=6.309, p=0.0032\end{array}$ \\
\hline Fig. $5 G$ & $\begin{array}{l}\text { Groups normally distributed, equal } \\
\text { variances }\end{array}$ & $\begin{array}{l}\text { Two-way ANOVA with } \\
\text { Bonferroni post hoc tests }\end{array}$ & $\begin{array}{l}\text { Age: } F_{(2,64)}=1.188, p=0.3113 ; \text { genotype: } F_{(1,64)}=2.193, p=0.1435 \\
\quad \text { interaction: } F_{(2,64)}=3.381, p=0.0402\end{array}$ \\
\hline
\end{tabular}




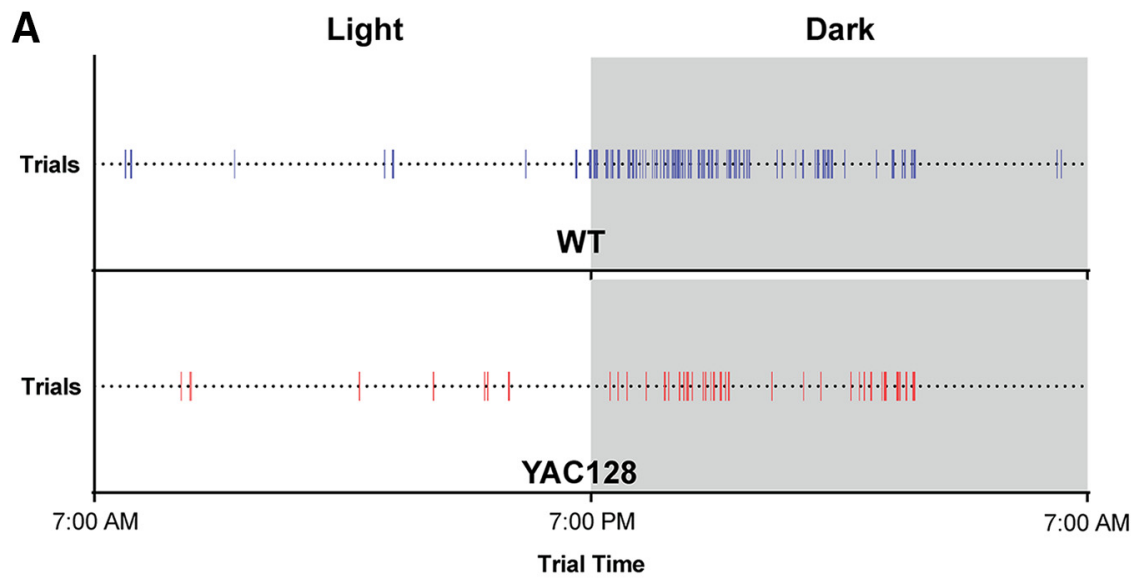

B

C

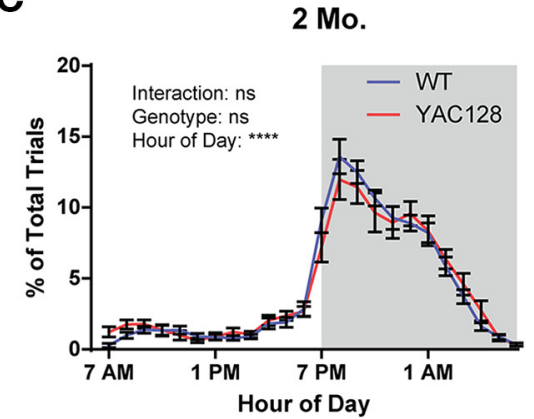

D

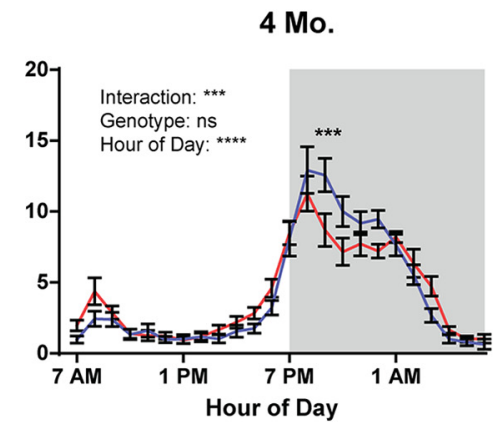

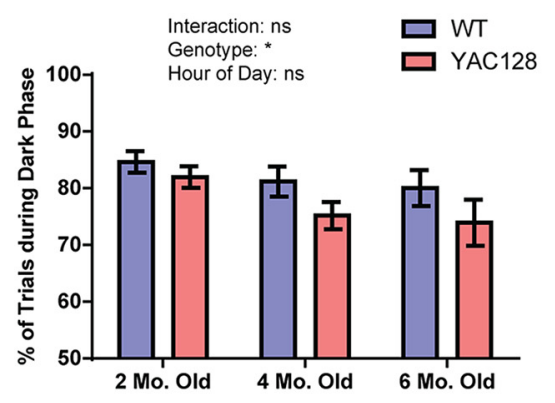

E

6 Mo.

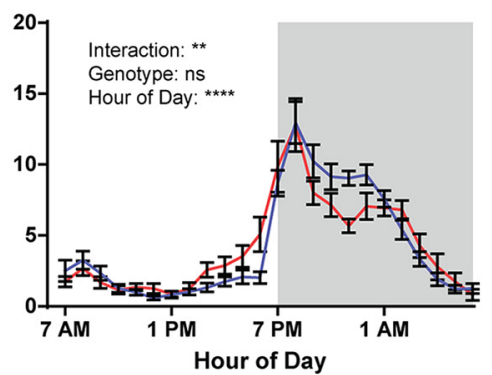

Figure 3. Distribution of trials throughout the light/dark cycle. $\boldsymbol{A}$, Raster plots show the distribution of trials through the day for representative four-month-old WT and YAC128 animals on the fifth day of testing (each line represents one trial). $\boldsymbol{B}$, The average percentage of all trials performed during the dark phase of testing was significantly higher in WT than in YAC128 mice, suggesting a disruption of normal circadian rhythms in these animals. $\boldsymbol{C}-\boldsymbol{E}$, Trials were split into 1-h bins for each animal, and the percentage of trials occurring in each bin was calculated and graphed for two-, four-, and six-month-old age groups. A significant interaction between genotype and the hour of day was observed for four- and six-month-old, but not two-month-old, animals. Numbers of animals (WT/YAC128) used for analysis are $n=17 / 13$ at two months old, $n=14 / 16$ at four months old, and $n=18 / 12$ at six months old. All data are presented as mean \pm SEM. ns $=$ not significant; $* p<0.5 ; * * p<0.01 ; * * * p<0.001 ; * * * * p<0.0001$.

ms). Conversely, animals that continued to perform their trials as in phase 1 did not advance.

While four- and six-month-old YAC128 animals showed an equivalent progression through the task to their WT counterparts, two-month-old YAC128 mice showed a markedly slower progression, remaining at a lower required hold duration for longer on average before advancing (interaction: $p$ $<0.0001$; genotype: $p=0.0184$; Fig. 4A-C). However, despite this slower progression, there were no genotype differences in the percentage of animals that eventually reached the maximum hold duration (Fig. 4D), suggesting that this was not a problem with meeting the physical demands of the task. This deficit in two-month-old YAC128 animals is also reflected in the overall success rate of these animals over the first 500 pulls of phase 2 (Fig. 4E). This group had a lower average success rate as compared to all other WT and YAC128 groups, although this difference was not significant $(p=0.0905)$.

\section{Six-month-old YAC128 mice have kinematic abnormalities when required to hold the lever for longer}

The change in performance of the task from phase 1 can be seen when looking at lever position traces of trials from WT and YAC128 animals that have reached the maximum hold duration (Fig. $5 A, B$ ). Instead of rapidly pulling back and then releasing, animals held the lever within the goal range for the designated amount of time, as was required to receive a reward. However, the strategy used to achieve this goal differed between WT and YAC128, specifically in the six-month-old group. Analysis of averaged traces revealed that WT animals at this age typically displace the lever to a point just past the center of the goal range, and hold it steady within this range until the end of the trial (Fig. 5C). In contrast, many six-monthold YAC128 mice pull the lever straight through the goal range, and then slowly allow it to return to its start position (Fig. 5D).

To quantify this, we took averages of several kinematic measures for each animal's successful trials at the maximum required hold duration. The first of these was the maximum displacement of the lever from its starting position (i.e. the distance the lever is pulled backwards). A larger average maximum displacement was seen with increasing age $(p=0.0477)$ with this effect largely driven by an age-related increase in the YAC128 mice (Fig. 5E). As we did not observe a significant genotype or interaction effect overall, post hoc comparisons could not be 
A

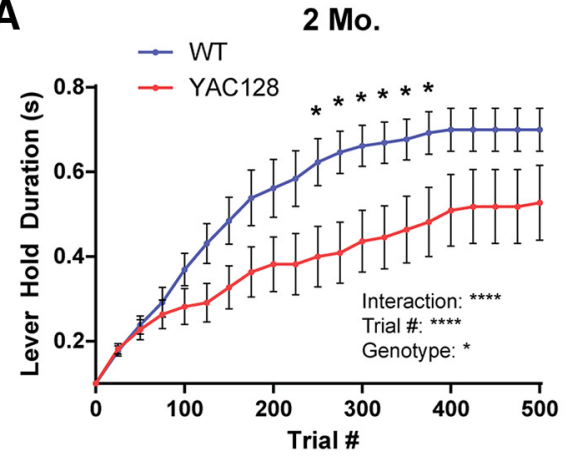

B

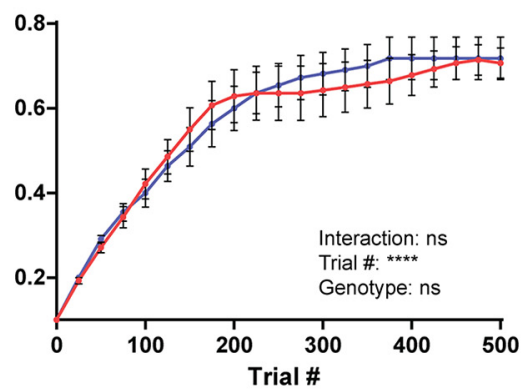

C
6 Mo.
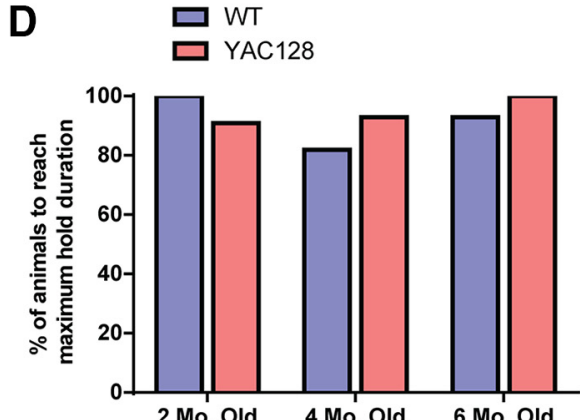

E
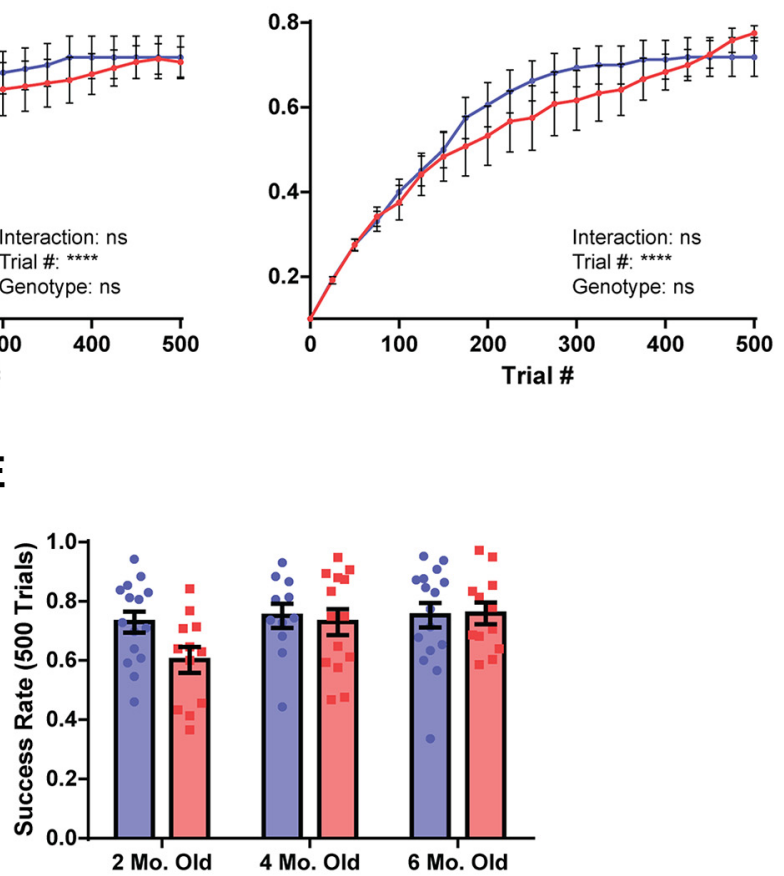

Figure 4. Performance of the task during phase 2. A-C, Progression to the maximum required hold duration over the first 500 trials of phase 2 is plotted for two-, four-, and six-month-old age groups. At the end of each 25-trial bin, success rate was calculated over these trials to determine whether the animal met the threshold for their required hold duration to increase. Data are plotted as the required lever hold duration reached at the end of each 25-trial bin. YAC128 mice at two months old, but not other ages, had a significantly slower progression over the first 500 trials as compared to WT controls. $\boldsymbol{D}$. The majority of animals reached the maximum hold duration within one week, and no significant differences were observed between genotypes. $\boldsymbol{E}$, Success rate of animals over the first 500 trials of phase 2 is plotted for each age group. Two-month-old YAC128 animals had the lowest average success rate over this period, although no significant main or interaction effects were found. Numbers of animals (WT/YAC128) used for analysis are $n$ $=15 / 12$ at two months old, $n=11 / 14$ at four months old, and $n=16 / 12$ at six months old. All data are presented as mean \pm SEM. $\mathrm{ns}=$ not significant; $* p<0.5 ; * * p<0.01 ; * * * p<0.001 ; * * * * p<0.0001$

performed between WT and YAC128 mice in any age group. However, a separate unpaired $t$ test found a significant increase in maximum lever displacement in the six-month-old YAC128 mice $\left(t_{(21)}=2.405, p=0.0255\right)$. During the subsequent 800 -ms lever hold period, sixmonth-old animals had a greater negative slope of their lever trajectory on average $(p=0.0330)$, reflecting the progressive release of the lever during task performance (Fig. 5F). An interaction between age and genotype was also found in the average speed of the lever during each trial $(p=0.0402)$ due to a WT-specific decrease in this measure across ages, however this was not significantly different in any individual age group (Fig. 5G).

\section{Discussion}

We present a fully automated home-cage methodology for investigating motor learning and movement kinematics in a mouse model of HD. We found that YAC128 HD mice display several distinct circadian, cognitive and motor abnormalities at different time points, although interestingly, some of these deficits did not progress with age as expected.

The first of these observed differences was that a larger proportion of YAC128 animals failed to reach the task performance criteria in our first phase of testing. One possibility is that YAC128 mice have a motor control deficit, and this performance failure reflects an inability to move the lever properly. However, many of these "noncriteria" animals initially performed trials but then quickly stopped, suggesting that physical ability to perform the task was not impaired. Additionally, this was not a progressive phenotype as might be expected if this was a motor control problem, as an equal number of animals at two and six months old failed to acquire the task. A second possibility is that this genotype difference may be due to a failure to learn the association between the lever response and water reward. Several papers have reported operant learning deficits in both YAC128 (Brooks et al., $2012 b$ ) and knock-in mouse models of HD (Trueman et al., 2007, 2008; Yhnell et al., 2016), supporting this first possibility. However, the majority of these deficits were related to the accuracy and reaction time of the HD animals. Significantly lower levels of task acquisition were only seen with a more difficult delayed matching to position task in HdhQ111 mice (Yhnell et al., 2016).

A final possibility is that these animals were capable of performing the response and learning the responseoutcome contingency, but had reduced motivation to work for access to water. Animals tested in the lever-cage 
A

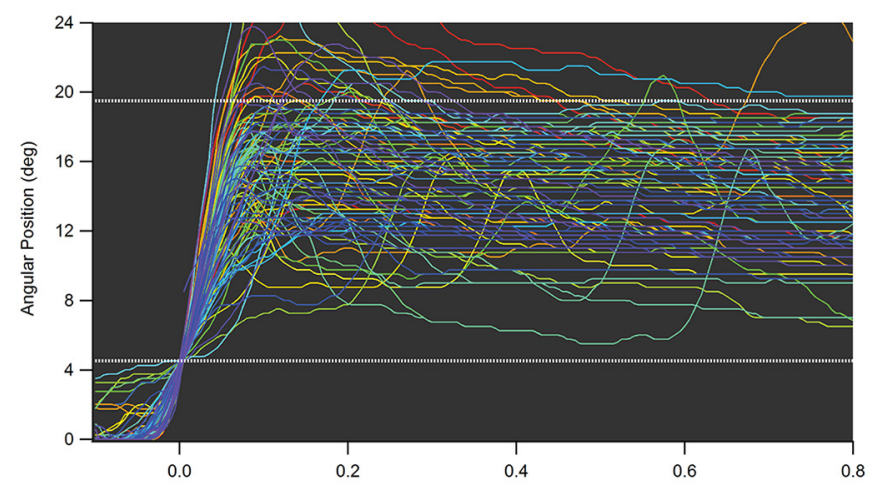

c

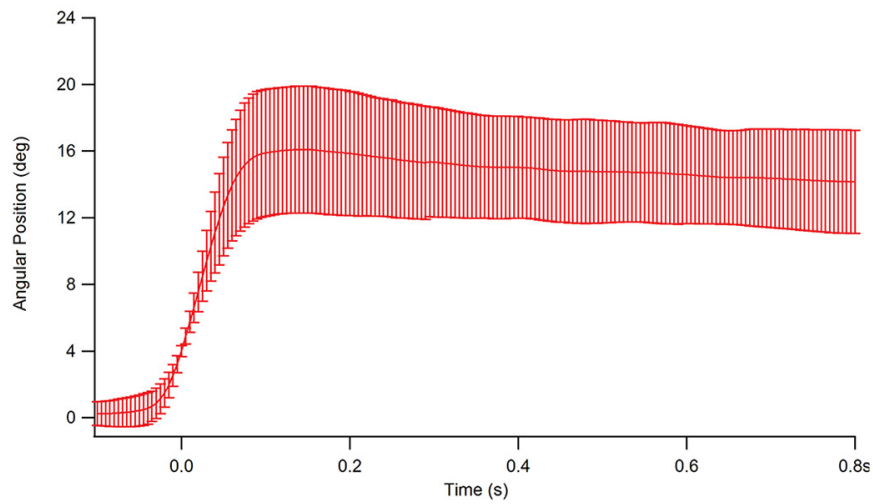

B

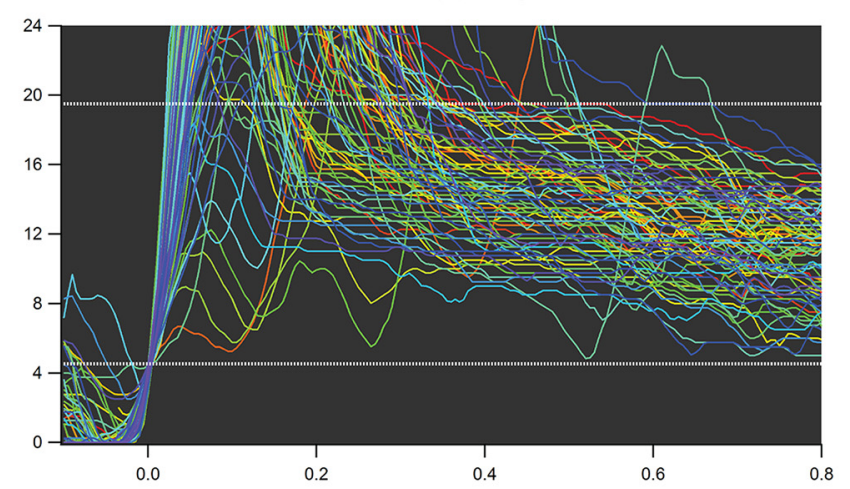

D

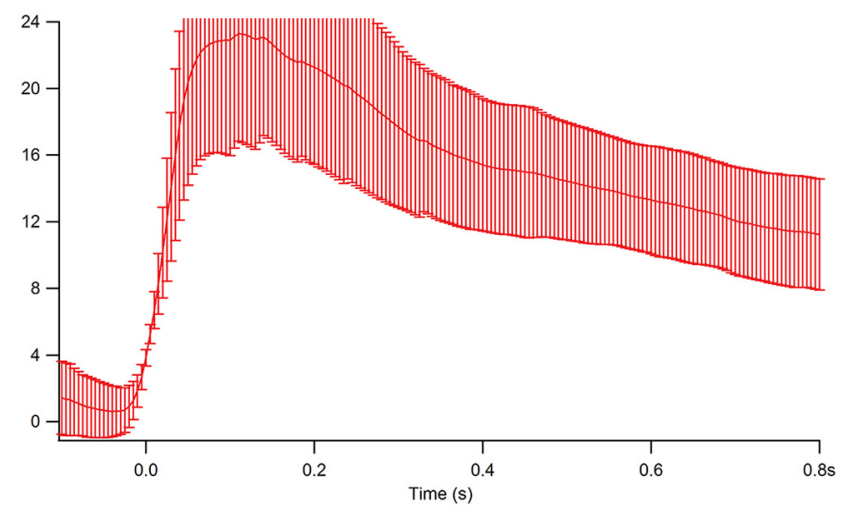

E

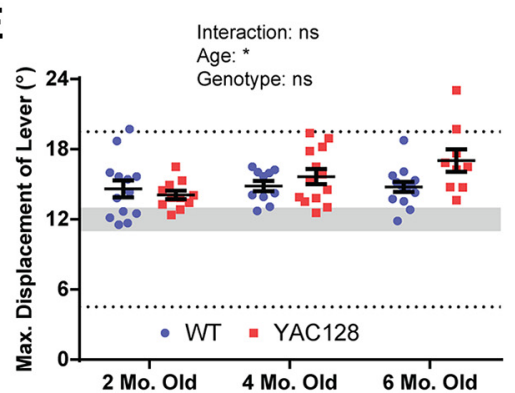

$F$

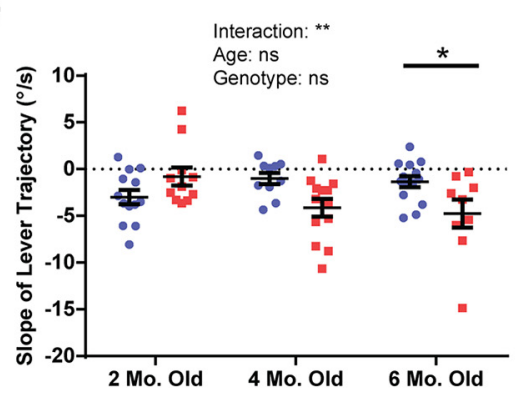

G

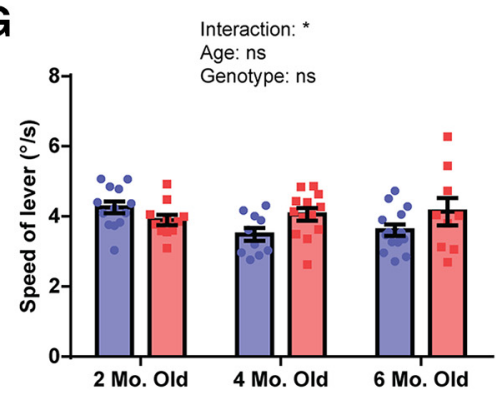

Figure 5. Kinematic measures of lever-pull trials at maximum hold duration. $\boldsymbol{A}, \boldsymbol{B}$, Lever position traces of 100 successful trials are shown for representative six-month-old WT and YAC128 mice who reached the maximum required lever hold duration. A tendency to overshoot the goal zone (dotted white lines) is seen in this YAC128 animal. $\boldsymbol{C}, \boldsymbol{D}$, Averaged lever position traces for the same two animals (error bars represent SD). $\boldsymbol{E}$, Average maximum displacement of the lever for all trials at the 800-ms hold duration is shown for WT and YAC128 animals. The shaded region represents the point at which a trial is initiated when pulled backwards $\left(12 \pm 1^{\circ}\right.$ from starting position), and the dotted lines represent the range it must be held within to receive a reward. A significant age effect was found, but not a significant genotype or interaction effect. $\boldsymbol{F}$, The average slope of the lever position trace from 200 to 800 ms after trial initiation was also calculated. An interaction between age and genotype was observed, and six-month-old YAC128 animals had a larger negative slope on average, indicating a progressive release of their hold on the lever. $\boldsymbol{G}$, The average speed of the lever over all trials at maximum hold duration. Although a significant interaction effect was seen, post hoc testing found no genotype differences in any of the age groups. Numbers of animals (WT/YAC128) used for analysis are $n=13 / 11$ at two months old, $n=10 / 13$ at four months old, and $n=14 / 9$ at six months old. All data are presented as mean \pm SEM except where indicated. ns $=$ not significant; $* p<0.5 ; * * p<0.01 ; * * * p<0.001$; ****p $<0.0001$.

received a minimal amount of water $(\sim 1 \mathrm{ml} / \mathrm{d})$ simply by entering the chamber. However, this is much less than the $\sim 3 \mathrm{ml} / \mathrm{d}$ that FVB/N and YAC128 mice consume when allowed ad libitum water access (Pouladi et al., 2009), and is equivalent to what is typically given on a water restriction protocol (Guo et al., 2014). A depressive phenotype has previously been reported in YAC128 animals when tested on forced swim and sucrose preference tests
(Pouladi et al., 2009, 2012), and so the failure of some animals to perform the task could be another reflection of these affective changes. This would be supported by the lack of age-related effects on this measure, as depressive and anhedonic phenotypes were not found to be progressive in these previous reports. Additionally, apathy, lack of motivation and depression are commonly reported in HD patients, and can occur long 
before the onset of motor symptoms (Kirkwood et al., 2001; Paulsen et al., 2001).

Weight fluctuations were observed in some animals during the first week of testing, especially in the sixmonth-old group. However, all animals (with the exception of one six-month-old YAC128 mouse) adapted to the restriction in water access and returned to within $5 \%$ of baseline weight by the end of testing (at minimum), suggesting that the change in ad libitum water access was well tolerated. The observed weight loss in older animals may be a reflection of this group having the highest baseline weight, and consequently highest dietary requirements for weight maintenance. In contrast, twomonth-old mice, and four-month-old YAC128 mice, continued to grow during the testing period. Younger animals also tended to perform more trials, and consequently received more water, in comparison to older animals. As two-month-old mice have a higher growth rate as compared to older animals, the increased task performance observed at this age may reflect a higher level of motivation for water as compared to the older groups (www.jax.org/jax-mice-and-services/strain-datasheet-pages/body-weight-chart-001800). While we have employed periodic manual weighing, it is notable that similar home-cages can be adapted to automated weighing and handling of up to 10 animals (Noorshams et al., 2017).

Abnormalities were also observed in YAC128 mice in the distribution of lever-pull trials over the course of the day. YAC128 mice performed more of their trials during the light phase overall, and subdividing trials into 1-h bins revealed distinct circadian irregularities specifically in the four- and six-month-old mice. While WT mice at these time points tended to have a very low percentage of their trials in the hours leading up to the start of the dark phase, YAC128 mice began to increase their performance of the task 3-4 $\mathrm{h}$ before this point. Furthermore, WT animals maintained a high performance rate over the first $6 \mathrm{~h}$ of the dark phase, whereas YAC128 mice began to decrease in their performance rate in the third hour. Circadian disruptions have been reported in patients with HD (Morton et al., 2005), as well as in several mouse models of HD, including R6/2, BACHD, and Q175 (Morton et al., 2005; Kudo et al., 2011; Oakeshott et al., 2011; Loh et al., 2013). However, similar circadian abnormalities have not previously been reported for YAC128 mice. Similarly to results published on other genetic lines, this is a progressive deficit and was not observed in the two-month-old animals. Although our task does not give a direct measure of overall activity level or locomotion, trial distribution through the day seems to provide a good proxy measure for this, and further confirms the disruptions observed in other genetic models.

In the second phase of testing, the success requirements of the task progressively changed, and animals were required to modify their motor response. The majority of animals were able to deal with these changes in task requirements and progressed quickly to the maximum required lever hold duration. However, two-month-old YAC128 mice had a significantly slower average progres- sion through the stages of the task as compared to WTs. This was not due to difficulties with the physical demands of the task, as these two-month-old animals showed no kinematic abnormalities and a similar percentage of them reached the maximum hold duration. Rather, this deficit seems to reflect a persistence in using the previously learned strategy instead of adapting their behavior to meet the new requirements. The observation of a motor learning deficit is not surprising in itself, as YAC128 mice as young as two months old have previously been found to have slower learning on a fixed speed rotarod task (Van Raamsdonk et al., 2005). A mild reversal learning deficit was also seen at two months old in the water T-maze, with more robust effects seen in animals at 8.5 months old and older (Van Raamsdonk et al., 2005; Brooks et al., 2012c), and our results could also be a reflection of impaired behavioral flexibility. However, what is more surprising is that the four- and six-month-old YAC128 mice did not show a similar impairment. As no differences were seen between the WT animals at different time points, this seems to reflect an early transient deficit of YAC128 mice at this age.

Several other phenotypes reported in young YAC128 mice have been seen to normalize to WT levels at later time points. For example, YAC128 animals display an early hyperkinetic phenotype in open field testing at three months old, before later decreasing in their open field activity to WT levels by six months old (Slow et al., 2003). At a physiologic level, an early increase in spontaneous EPSCs has been reported in dopamine D1 receptorexpressing medium spiny neurons (MSNs) of YAC128 mice at 1.5 months of age; however, this is reduced to WT levels in six-month-old animals (André et al., 2011). Furthermore, modulation of spontaneous activity by D1 receptor activation was found to be lost in acute slices from YAC128 mice at 1.5 months old, but restored at six months old (André et al., 2011). D1 receptor function in direct pathway MSNs is an important regulator of synaptic plasticity (Kreitzer and Malenka, 2008), and it is possible that the motor learning deficit we observe is linked to overactivation and loss of synaptic plasticity at these striatal inputs. Another factor that may be contributing to this early and transient behavioral phenotype is changes in the activity and expression of the adenosine A2a receptor. An increased density of this receptor is seen in very young R6/2 HD mice (Tarditi et al., 2006) and knockout of A2aR was found to reverse working memory deficits in young R6/2 mice (Li et al., 2015). Interestingly, A2a receptor inactivation is also linked to improvements in behavioral flexibility and reversal learning (Wei et al., 2011), and so the presence of an early increase in expression, if present in YAC128 mice, could help to account for the observed motor learning deficit.

The presence of these early and transient phenotypes in HD mice suggests that multiple parallel pathophysiological processes may underlie the progression of motor phenotypes in HD. One possibility is that the behavioral changes observed in young HD mice are a direct effect of the huntingtin mutation which is later compensated for during the early disease progression. Alternatively, behavioral phenotypes might be caused by an early compen- 
satory process, and failure of compensation at later stages results in apparent normalization of the behavior. In either case, this suggests that separate and independent processes, as well as eventual neurodegeneration, may cause the slower and progressive development of cognitive and motor phenotypes observed in older (more than four months old) YAC128 mice.

In addition to assessing motor learning, the second primary objective of our study was to investigate the possibility of task-related kinematic abnormalities in YAC128 mice. Mild motor deficits have previously been observed in five- to six-month-old YAC128 mice on the rotarod, horizontal ladder and narrow beam tests (Van Raamsdonk et al., 2005; Di Pardo et al., 2012). However, assessments of skilled motor performance, such as reach-to-grasp and lever-pulling tests, have been infrequently used in genetic models of neurodegenerative disorders. Kinematic analysis of HD models has been primarily focused on gait abnormalities, although these are subtle in the YAC128 model and have only been observed in animals over one year old (Chen et al., 2011). In our task, we found that six-month-old YAC128 animals displayed irregularities in the performance of their trials as compared to WT animals in the second phase of testing. Specifically, many animals were unable to keep the lever at a steady position within the goal range, and progressively released their hold on it over the course of each trial. It seems likely from this behavior that these animals are compensating for a lack of control, and have difficulty maintaining a constant force while holding the lever. This phenotype may be analogous to motor impersistence, a common movement abnormality seen in patients with HD which is characterized by an inability to maintain a constant strength during muscle contractions (Walker, 2007). Motor impersistence is seen in nearly all HD patients, and unlike other primary motor symptoms (such as chorea), it is typically linearly progressive with the disease course (Reilmann et al., 2001). As such, the ability of the cage-system to detect an analogous phenotype in mice is promising for future studies of HD models, and to our knowledge, these results are the first to show such a task-related kinematic abnormality in a mouse model of HD.

In summary, our results further build on the behavioral profile of YAC128 animals at a relatively early phenotypic stage by using an automated and continuously accessible operant motor learning task. These results further validate the use of YAC128 as a model for HD, as we observed several novel phenotypes in these animals that parallel the human disease, including circadian abnormalities and changes in motor behavior on a skilled motor task. This study also provides further evidence for the efficacy of both home-cage assessment, and motor learning tasks for the high-throughput identification of behavioral phenotypes in rodent models of disease.

\section{References}

Abada YS, Ellenbroek BA (2016) Of rodents and men: understanding the emergence of motor and cognitive symptoms in Huntington disease. Behav Pharmacol 27:403-414. CrossRef Medline

Alexandrov V, Brunner D, Menalled LB, Kudwa A, Watson-Johnson J, Mazzella M, Russell I, Ruiz MC, Torello J, Sabath E, Sanchez A,
Gomez M, Filipov I, Cox K, Kwan M, Ghavami A, Ramboz S, Lager B, Wheeler VC, Aaronson J, et al. (2016) Large-scale phenome analysis defines a behavioral signature for Huntington's disease genotype in mice. Nat Biotechnol 34:838-844. CrossRef Medline André VM, Cepeda C, Fisher YE, Bardakjian N, Singh S, Yang XW, Levine MS (2011) Differential electrophysiological changes in striatal output neurons in Huntington's disease. J Neurosci 31:11701182. CrossRef Medline

Balci F, Oakeshott S, Shamy JL, El-Khodor BF, Filippov I, Mushlin R, Port R, Connor D, Paintdakhi A, Menalled L, Ramboz S, Howland D, Kwak S, Brunner D (2013) High-throughput automated phenotyping of two genetic mouse models of Huntington's disease. PLoS Curr 5.

Bolaños F, LeDue JM, Murphy TH (2017) Cost effective raspberry pi-based radio frequency identification tagging of mice suitable for automated in vivo imaging. J Neurosci Methods 276:79-83. CrossRef Medline

Brooks SP, Higgs G, Janghra N, Jones L, Dunnett SB (2012a) Longitudinal analysis of the behavioural phenotype in YAC128 (C57BL/6J) Huntington's disease transgenic mice. Brain Res Bull 88:113-120.

Brooks SP, Jones L, Dunnett SB (2012b) Longitudinal analyses of operant performance on the serial implicit learning task (SILT) in the YAC128 Huntington's disease mouse line. Brain Res Bull 88:130-136.

Brooks SP, Janghra N, Higgs GV, Bayram-Weston Z, Heuer A, Jones L, Dunnett SB (2012c) Selective cognitive impairment in the YAC128 Huntington's disease mouse. Brain Res Bull 88:121-129.

Chen X, Wu J, Lvovskaya S, Herndon E, Supnet C, Bezprozvanny I (2011) Dantrolene is neuroprotective in Huntington's disease transgenic mouse model. Mol Neurodegener 6:81. CrossRef Medline

Di Pardo A, Maglione V, Alpaugh M, Horkey M, Atwal RS, Sassone J, Ciammola A, Steffan JS, Fouad K, Truant R, Sipione S (2012) Ganglioside GM1 induces phosphorylation of mutant huntingtin and restores normal motor behavior in Huntington disease mice. Proc Natl Acad Sci USA 109:3528-3533. CrossRef

Fenrich KK, May Z, Hurd C, Boychuk CE, Kowalczewski J, Bennett DJ, Whishaw IQ, Fouad K (2015) Improved single pellet grasping using automated ad libitum full-time training robot. Behav Brain Res 281:137-148. CrossRef Medline

Guo ZV, Hires SA, Li N, O'Connor DH, Komiyama T, Ophir E, Huber D, Bonardi C, Morandell K, Gutnisky D, Peron S, Xu N, Cox J, Svoboda K (2014) Procedures for behavioral experiments in headfixed mice. PLoS One 9:e88678. CrossRef Medline

Hånell A, Marklund N (2014) Structured evaluation of rodent behavioral tests used in drug discovery research. Front Behav Neurosci 8:252. CrossRef Medline

Huntington's Disease Collaborative Research Group (1993) A novel gene containing a trinucleotide repeat that is expanded and unstable on Huntington's disease chromosomes. Cell 72:971-983.

Julien CL, Thompson JC, Wild S, Yardumian P, Snowden JS, Turner G, Craufurd D (2007) Psychiatric disorders in preclinical Huntington's disease. J Neurol Neurosurg Psychiatry 78:939-943. CrossRef Medline

Kirkwood SC, Su JL, Conneally PM, Foroud T (2001) Progression of symptoms in the early and middle stages of Huntington disease. Arch Neurol 58:273-278. Medline

Kreitzer AC, Malenka RC (2008) Striatal plasticity and basal ganglia circuit function. Neuron 60:543-554. CrossRef Medline

Kudo T, Schroeder A, Loh DH, Kuljis D, Jordan MC, Roos KP, Colwell CS (2011) Dysfunctions in circadian behavior and physiology in mouse models of Huntington's disease. Exp Neurol 228:80-90. CrossRef Medline

Li W, Silva HB, Real J, Wang YM, Rial D, Li P, Payen MP, Zhou Y, Muller CE, Tomé AR, Cunha RA, Chen JF (2015) Inactivation of adenosine A $2 \mathrm{~A}$ receptors reverses working memory deficits at early stages of Huntington's disease models. Neurobiol Disease 79:70-80. CrossRef Medline 
Loh DH, Kudo T, Truong D, Wu Y, Colwell CS (2013) The Q175 mouse model of Huntington's disease shows gene dosage-and age-related decline in circadian rhythms of activity and sleep. PLoS One 8:e69993. CrossRef

Mandillo S, T ucci V, Hölter SM, Meziane H, Banchaabouchi MA, Kallnik M, Lad HV, Nolan PM, Ouagazzal AM, Coghill EL, Gale K, Golini E, Jacquot S, Krezel W, Parker A, Riet F, Schneider I, Marazziti D, Auwerx J, Brown SD, Chambon P, Rosenthal N, Tocchini-Valentini G, Wurst W (2008) Reliability, robustness, and reproducibility in mouse behavioral phenotyping: a crosslaboratory study. Physiol Genomics 34:243-255. CrossRef Medline

Menalled L, El-Khodor BF, Patry M, Suárez-Fariñas M, Orenstein SJ, Zahasky B, Leahy C, Wheeler V, Yang XW, MacDonald M, Morton AJ, Bates G, Leeds J, Park L, Howland D, Signer E, Tobin A, Brunner D (2009) Systematic behavioral evaluation of Huntington's disease transgenic and knock-in mouse models. Neurobiol Disease 35:319-336. CrossRef Medline

Menalled L, Lutz C, Ramboz S, Brunner D, Lager B, Noble S, Park L, Howland D (2014) A field guide to working with mouse models of Huntington's Disease. Bar Harbor: PsychoGenics Inc., The Jackson Laboratory, CHDI Foundation.

Morton AJ, Wood NI, Hastings MH, Hurelbrink C, Barker RA, Maywood ES (2005) Disintegration of the sleep-wake cycle and circadian timing in Huntington's disease. J Neurosci 25:157-163. CrossRef Medline

Murphy TH, Boyd JD, Bolaños F, Vanni MP, Silasi G, Haupt D, LeDue JM (2016) High-throughput automated home-cage mesoscopic functional imaging of mouse cortex. Nat Commun 7:11611. CrossRef

Noorshams O, Boyd JD, Murphy TH (2017) Automating mouse weighing in group homecages with Raspberry $\mathrm{Pi}$ microcomputers. J Neurosci Methods 285:1-5. CrossRef Medline

Oakeshott S, Balci F, Filippov I, Murphy C, Port R, Connor D, Paintdakhi A, LeSauter J, Menalled L, Ramboz S, Kwak S, Howland D, Brunner D (2011) Circadian abnormalities in motor activity in a BAC transgenic mouse model of Huntington's disease. PLoS Curr 3:RRN1225.

Paulsen JS, Ready RE, Hamilton JM, Mega MS, Cummings JL (2001) Neuropsychiatric aspects of Huntington's disease. J Neurol Neurosurg Psychiatry 71:310-314. Medline

Paulsen JS, Langbehn DR, Stout JC, Aylward E, Ross CA, Nance M, Guttman M, Johnson S, MacDonald M, Beglinger LJ, Duff K, Kayson E, Biglan K, Shoulson I, Oakes D, Hayden M; Predict-HD Investigators and Coordinators of the Huntington Study Group (2008) Detection of Huntington's disease decades before diagnosis: the Predict-HD study. J Neurol Neurosurg Psychiatry 79:874880. CrossRef Medline

Pouladi MA, Graham RK, Karasinska JM, Xie Y, Santos RD, Petersén $\AA ̊$, Hayden MR (2009) Prevention of depressive behaviour in the
YAC128 mouse model of Huntington disease by mutation at residue 586 of huntingtin. Brain 132:919-932.

Pouladi MA, Stanek LM, Xie Y, Franciosi S, Southwell AL, Deng Y, Butland S, Zhang W, Cheng SH, Shihabuddin LS, Hayden MR (2012) Marked differences in neurochemistry and aggregates despite similar behavioural and neuropathological features of Huntington disease in the full-length BACHD and YAC128 mice. Hum Mol Genet 21:2219-2232. CrossRef Medline

Pouladi MA, Morton AJ, Hayden MR (2013) Choosing an animal model for the study of Huntington's disease. Nat Rev Neurosci 14:708-721. CrossRef Medline

Reilmann R, Kirsten F, Quinn L, Henningsen H, Marder K, Gordon AM (2001) Objective assessment of progression in Huntington's disease: a 3-year follow-up study. Neurology 57:920-924. Medline

Sindhurakar A, Butensky SD, Meyers E, Santos J, Bethea T, Khalili A, Sloan AP, Rennaker RL, III, Carmel JB (2017) An automated test of rat forelimb supination quantifies motor function loss and recovery after corticospinal injury. Neurorehabil Neural Repair 31:22-132. CrossRef

Slow EJ, Van Raamsdonk J, Rogers D, Coleman SH, Graham RK, Deng Y, Oh R, Bissada N, Hossain SM, Yang YZ, Li XJ, Simpson EM, Gutekunst CA, Leavitt BR, Hayden MR (2003) Selective striatal neuronal loss in a YAC128 mouse model of Huntington disease. Hum Mol Genet 12:1555-1567. CrossRef

Tarditi A, Camurri A, Varani K, Borea PA, Woodman B, Bates G, Cattaneo E, Abbracchio MP (2006) Early and transient alteration of adenosine $\mathrm{A} 2 \mathrm{~A}$ receptor signaling in a mouse model of Huntington disease. Neurobiol Disease 23:44-53. CrossRef

Trueman RC, Brooks SP, Jones L, Dunnett SB (2007) The operant serial implicit learning task reveals early onset motor learning deficits in the Hdh knock-in mouse model of Huntington's disease. Eur J Neurosci 25:551-558. CrossRef

Trueman RC, Brooks SP, Jones L, Dunnett SB (2008) Time course of choice reaction time deficits in the $\mathrm{Hdh}(\mathrm{Q} 92)$ knock-in mouse model of Huntington's disease in the operant Serial Implicit Learning Task (SILT). Behav Brain Res 189:317-324. CrossRef Medline

Van Raamsdonk JM, Pearson J, Slow EJ, Hossain SM, Leavitt BR, Hayden MR (2005) Cognitive dysfunction precedes neuropathology and motor abnormalities in the YAC128 mouse model of Huntington's disease. J Neurosci 25:4169-4180. CrossRef Medline

Walker FO (2007) Huntington's disease. Lancet 369:218-228. CrossRef Medline

Wei CJ, Singer P, Coelho J, Boison D, Feldon J, Yee BK, Chen JF (2011) Selective inactivation of adenosine A2A receptors in striatal neurons enhances working memory and reversal learning. Learn Mem 18:459-474. CrossRef

Yhnell E, Dunnett SB, Brooks SP (2016) The utilisation of operant delayed matching and non-matching to position for probing cognitive flexibility and working memory in mouse models of Huntington's disease. J Neurosci Methods 265:72-80. CrossRef Medline 